\title{
A descriptive algorithm for a wine tasting lexicon corpus
}

Un algoritmo descriptivo para un corpus léxico sobre cata de vinos

\author{
Margarita Goded Rambaud
}

UNED, Senda del Rey, 7 Madrid 28040, Margarita.goded@flog.uned.es

\begin{abstract}
Resumen
Se presenta un algoritmo descriptivo para un corpus léxico de cata de vinos. Primero, se presentan algunas características idiosincrásicas del corpus. En segundo lugar, se discute la similitud estructural de las ontologías, gramáticas y el algoritmo propuesto. En tercer lugar, se debate la propuesta de Langacker de separar ontológicamente entre objetos e interacciones. Finalmente, se discute una propuesta de etiquetado anotativo y se presentan algunos ejemplos.
\end{abstract}

Palabras clave: Ontologías. Cata de vinos.

\section{Introduction}

This paper is organized as follows. Firstly, some characteristics of the lexical field where the corpus will be obtained are shown. Secondly, the claim of the structural similarity of ontologies, grammars and the proposed algorithm is discussed. Thirdly, Langacker's ontological separation between objects and interactions is debated. And, finally, a proposal for tagging annotation will be discussed in a few examples.

\section{Sensory background for wine tasting lexicons}

The analysis of the characteristics of the wine tasting lexicon has been approached starting from the general procedure for sensory analysis. The conventional wine tasting procedure includes three stages in which the senses of sight, smell and taste participate in this precise sequence.

There are some characteristics that define the sense of odour and which neurologically differentiate it from other senses. This differentiation is shown in various ways and it affects the idiosyncratic verbalization of this sensory experience. Sensory description of visual perception adopts a type of lexicalization which in some languages includes both colour nominalization and adjectivation. Colour adjectives include an extensive range of colour descriptors. Even if there are

\begin{abstract}
A descriptive algorithm for a wine tasting lexicon corpus is presented. Firstly, some characteristics of the lexical field where the corpus will be obtained are shown. Secondly, the claim of the structural similarity of ontologies, grammars and the proposed algorithm is discussed. Thirdly, Langacker's ontological separation between objects and interactions is debated. And, finally, a proposal for tagging annotation will be discussed in a few examples.
\end{abstract}

Keywords: Ontologies. Wine tasting.

languages where basic referents for colours and their descriptors are the same, both Spanish and English have lexicalized them separately. Most languages have also gone through a similar abstraction process. That is, the sense of sight codifies colour separately from the referents having these colours. Both Spanish and English pairings

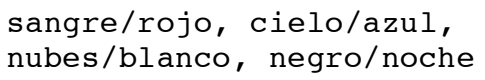

$\mathrm{blood/red,} \mathrm{sky/blue,}$

clouds/white, night/black

show the highly anthropocentric origin of the referents and how referents and colour description are separately lexicalized.

Similarly, there are also terms which describe the abstraction of a tasting sensation which have been lexicalized in the basic tasting terms sweet, sour, salty, bitter (Spanish dulce, ácido, salado, amargo ), again understood both as attributive adjectives or nouns. A separate lexicalization of referents as sources of sensory experience is shown in the following pairings:

$$
\begin{aligned}
& \text { azucar/dulce, limón/ácido, } \\
& \text { sal/salado, vinagre/amargo }
\end{aligned}
$$

and

sugar/sweet, yougurt/sour, salt/salty, vinegar/bitter 
However the generic terms in both languages for smell subdivide broadly into:

smell: aroma-fragance/stench

olor: aroma-fragancia/hedor

The only kind of lexicalization that appears to be possible at this stage is a basic discrimination between pleasant / unpleasant odours. A basic discrimination/differentiation between acceptance and rejection of an odour, could possibly be related to survival and evolutionary constraints.

As the research gathered by G. Morot, F. Brochet and D. Dubourdieu (2001) (1) shows, there are a number of factors that influence the complexity of the smell sensory experience. They have also explored verbal categorization in the sense of smell and explain that, in contrast with other sensory modalities, the fact that there are no specific terms-different from their respective sources-to designate odours confirm their hypothesis of the neurologically weak association between smell and language.

Morot et al., also suggest that the weak connection between odours and language is probably due to the brain lateralization which takes place in the processing of odours and its lexicalization. They add that, while language processing takes place in the left side of the brain for most people, the processing of odours is right lateralized. They also afirm that the sense of smell is unlikely to provide enough information to generate sounded decisions in contrast with the information provided by other senses. As a result, the vast majority of odours take the name of the objects emitting these odours.

They found that the strong influence sight has over the other senses produces certain alterations and they analyzed the empirical evidence they gathered in the smell phase of a blind taste performed by wine professionals. In their experiment they showed how, when red wines were dyed with tasteless and decolouring chemicals, professional enologists were unable to differentiate the reds from the whites. That is, they produced strong evidence of the dependence of smell on the information provided by other senses.

Odours then are described either using the term for the object that emits that particular odour or using metaphorical / metonymic descriptions, wine tasting notes frequently use combinations of both.

Viberg 1984 proposes the following hierarchy for sense codification: sight $>$ hearing $>$ touch $>$ smell > taste.
He demonstrated that a verb that has its basic meaning in a sensory modality to the left in the hierarchy, may have an extended meaning covering some or all sensory modalities below in such a hierarchy.

$\mathrm{He}$ also studied the range of cognitive meanings of perception verbs analyzing the use of see and the fact that both see and know cover the same meaning and are in fact the same verb in various languages. The metaphoric use of see and know has been widely documented in the cognitive literature ( Lakoff, Miller and Johnson-Laird, 1976) and it allowed a new perspective of the interpretation of verbs of perception.

However it was not until Sweetser's (1990) and Popova's (2003) works appeared that this metaphoric verbal extensions were considered as systematic rather that anecdotic. Sweetser applies the Lakovian notion of embodiment to build the conceptual metaphor MIND-AS-BODY. As is well known, this means that our understanding of the cognitive domain lays on the systematic correspondences between the domain of the body and the domain of the mind. She shows how there is a double correspondence in verbs of perception between physical perception and states of the mind and explains how, when using a traditional componential analysis in the semantic description of these verbs, there are no shared identifiable meaning components between the features defining see and know. The only systematic correspondence must be identified in our common experience of seeing and knowing.

As mentioned above, languages such as Spanish or English codify the so called higher senses, separating referents and their lexicalization by means of nouns and adjectives. It is the case that the codification of sight in these two languages is lexicalized in a similar way. Both languages use the same term for the noun in the name of the colour and for the corresponding adjective, although they both use in each language different grammaticalization structures for adjectivation. Possibly because, as argued by Paradis (2005), nouns and adjectives can be based on the same types of content structure, but they are differently construed in all cases which is why they are traditionally categorized as two different parts-of-speech in languages that make that distinction.

That is, since the same conceptual content can be construed profiling either an entity or a relation, both nouns and adjectives can be used depending on the different level of abstraction required by the communicative interaction. 
An this is why particular aspects of a wine tasting are made salient using a variety of construals under development. Highlighting either entities or relations is something that can be achieved in a number of ways. Metonimization, abstraction, summary and sequential scanning and profiling are all special cases of construals of salience (Paradis, ibidem), that are involved in the construction of any ontology and, particularly, in the construction of a possible ontology of the subfield of wine tasting.

\section{Structural similarity of ontologies, grammars and the proposed algorithm}

It was initially hypothesized that a lexical field can be described in terms of the ontology of that particular field and that this description can take the form of a grammar which can, eventually, take the form of a descriptive algorithm. Because these three theoretical constructs share the same basic structure, it is argued here that they can be reduced to each other.

Ontologies, in any format, include a number of entities and identify and describe the relations that link them. Definitions both from philosophy and from computational sciences include the reference to the identification of entities of all kinds (abstract or concrete) and the relations among these entities.

On the other hand, in the most traditional of its definitions, the description of a grammar includes the identification of a series of categories valid for that particular language. For example, adjectives for languages that have this category, cases, etc. and a number of rules of use of such categories. That is, a grammar of language establishes the categories which operate in that particular language and identify and describe the rules which relate the identified categories for this language.

Finally, a compilation of different definitions of the term algorithm results into a general inclusion of features such as a set of instructions or rules, that apply to a set of elements, with a definite purpose and in a particular sequence. For example, a cooking recipe includes the following:

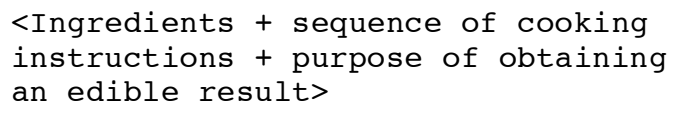

That is the three conceptual constructs share the same basic mathematical structure:

$$
\mathrm{F}(\mathrm{x}), \mathrm{a} \ldots . . \mathrm{n}
$$

Consequently it is argued here that these conceptual constructs are mutually equivalent and, because of this, the identification of because of this, the identification of components in a descriptive algorithm becomes highly relevant.

It can be argued then that the set of instructions that apply to a number of lexical entries, with the clearly defined purpose of transmit some information, is basically a descriptive algorithm of the type:

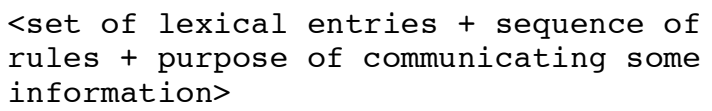

\subsection{The issue of sequentiality}

It is a well known fact that sequentiality or linearity, is a crucial property for symbolic systems such as language because certain logical and mathematical properties such as transitivity depend on this characteristic.

Since all human information processing can be fed into the system either in a simultaneous or in a sequential mode, sequentiality operates differently in the input and in the output stages of language processing and elicitation. That is, when a piece of language is processed, both contextual and audial information is simultaneously processed. However, linguistic elicitation takes place in a sequential mode only. Sequentiality or linearity is a particular characteristic of all human languages and this fact was originally identified by Saussure. Syntagmatic relations constitute a direct consequence of this particular specificity of human languages. Sequenciality then should take the form of a rule such that for each lexical piece sequentiality is or is not applicable.

The agglutination of this information is quite simple and it is only subject to one general specification or generic rule affecting sequentiality. Since ontologies are conceived of as hierarchisized conceptual descriptions, sequenciality operates in hierarchies as well as in linear structures.

This is important from the computational point of view because, if sequentiality is not applied at a certain point of the structure, it will rule out the activation of the content of various subsequent slots in the hierarchy as irrelevant.

As a result, the sequencing of the elements to be inserted and the sequencing of the instructions both determine the structure of the descriptive algorithm.

Ontologies, as linguistically and computationally related objects, are conceived of as hierarchisized conceptual descriptions where sequentiality is or is not applicable. 


\subsection{Semantic and ontological perspectives} to be considered in the field

Although a broad Cognitive approach in the line of Langacker is ackowledged as pervasive influence for this work, this paper's theoretical background does not hold strong affiliations with any particular linguistic theory. Furthermore, no attempt has been made to try to fit this kind of tagging into a particular linguistic model. On the contrary a mild claim is been posed here in the sense that most existing grammars or linguistic models contribute to lexical representation of meaning in a variety of ways and that these variations should be accounted for rather than obliterated.

However, Langacker's influence does not come without problems. Langacker (1991, p. 16) differentiates between objects and interactions quite clearly. Objects are instantiated in space, having spatial locations, are discrete, and are stable along time and space. In addition, objects are defined as conceptually autonomous whereas interactions are defined as conceptually dependent in the sense that interactions do not exist independently of its participants.

Langacker develops his analysis introducing the term "entity" which he defines as

anything one might refer to for analytical purposes: objects, relationships, locations, sensations, points on a scale, distances, etc. Crucially, it is not required that an entity be discrete, individually recognized, or cognitively salient...

That is, after having differentiated between objects and interactions, both concepts become interchangeable. It seems as if the basic ontological differentiation between entities and relations should be avoided. As a result, this differentiation is invalidated since his definition for entities includes now both objects and relationships.

Further down he explains that,

It is not the character of individual entities that is important, but rather the fact that they are interconnected and thereby constitute a region.

which is precisely why entities must be separate from relations. Or, alternatively, his previous differentiation between objects and interactions maintained.

But this is not the case and the use of the term "entity" including the concept of relationship is permeating further discussion and, to my view, misleading it. Particularly because, after listing what qualifies as entity (objects, relationships, locations, sensations, points on a scale, distances, etc), he explains that any expanse of material substance qualifies as an entity, thus highlighting objects and not relationships.

Since this basic differentiation operates in the organization of any ontology it is unclear what would be the advantage of subsuming it in a more comprehensive concept or dispensing of it altogether.

Ontologies, either in their computational form or in their primary philosophy oriented configuration, are basically a set of entities that can be defined within a prefixed area of knowledge and a set of relations that can also be defined within the same area of knowledge. For the purpose of analyzing the particular semantic field of wine lexicon, the definition for ontology taken here includes the primary differentiation between entities and interactions in the line of Langaker's (1991, p. 14). In addition, if we understand ontologies as "a manageable instrument in the design of databases" (Paradis, 2005), these two concepts should be kept apart firstly for the sake of clarity in the analysis and, secondly for both mental processing and computational reasons.

Whether the mind construes entities highlighting its relational, temporal, internal structure, such as, for instance, in the case of "property", or highlighting its atemporal character, as Langacker proposes, is a another kind of analysis that can be attempted elsewhere. What is emphasized at this stage is only the fact that entities and the relations that can be identified among them, constitutes a previous stage of analysis that the human mind is able to perform even before a subsequent linking of this differentiation to several parts of speech in the languages of the world is attempted.

In this differentiation, it is the abstract nature of second-order entities what is highlighted precisely because their relational nature is not. And precisely because of this, an ontology, as methodologically providing us with manageable instrument in the design of a database, must make a preliminary distinction between entities-of whatever kind-and relations as an starting premise.

\section{Semantic / cognitive tagging proposal}

Ontological semantics is based on the assumption that it is possible to reduce any natural language utterance to a formalized, language neutral representation (Moreno \& Pérez 2002). Since an ontology's main objective is to make explicit the conceptual organization of a particular field, they could be considered language independent. But, on the other hand, this knowl- 
edge is lexicalized in particular languages of the world.

Presently, the study of this lexicalization is restricted only to a Spanish data base and its English translation. It is this lexicalization what allows a corpus treatment which, consequently, can be annotated. Therefore, the type of annotation proposed here is field based and its purpose is to identify the different linguistic and non linguistic components which, at different degrees of influence and at different levels of abstraction, contribute to create the meaning of an expression.

It is claimed here that the ontological requirements of particular fields of knowledge and/or experience together with the characteristics of the corpora determine the appropriate selection of annotation. That is, the tagging components that the annotation of the corpus requires are field dependent.

While language independent tagging components are more closely linked to ontologies, language dependent annotation is related to corpora. Both types of components make up a set of elements which constitute a proposed descriptive algorithm for the field. I make the claim that this descriptive algorithm includes all the specifications that the system needs to process the information needed and I also take the view that language dependent tagging components constitutes a type of limited grammar

The proposed descriptive algorithm is just an agglutination of components subject only to a general rule of organization. It is the selection of components and this general requirement what constitutes this limited grammar.

As in any ontology, two elements should be previously identified for this area of experience. One refers to the kind of entities present in the semantic field under study and the other to the type of relations that hold among these entities. An ontology describing the area of knowledge of food and wine is no exception.

Ways of accounting for sensory description making extensive use of synesthesia, metaphor and metonymy and ways of accounting for this in a proposed descriptive algorithm should be identified. This task is worthwhile to the extent that its findings can be extrapolated to other lexical fields but, most importantly, because some of these findings could be interpreted as contributions to a more general model of lexical representation.

The preliminary distinction between linguistic dependent and linguistic independent knowledge representations is again applied now. The fact that semantic descriptions are usually pla- placed at a higher level of abstraction compared with syntactic descriptions does not mean that the former is linguistically independent. Most semanticists from all affiliations agree that semantic description is lexically dependent and that it is also syntactically based. The interface syntax-semantics operates syntagmatically at one key point, that is where the argument structure fixes the type of contents to be acceptable in each argument slot. As a result, each verbal lexical predicate determines certain theta-roles configurations. This means that only a selection of components to be considered as descriptors in the proposed descriptive algorithm can be language independent; that is, the link to perceptual input and the logically based section of it codified in terms of entities and relations. All the rest is language dependent.

Since meaning is encoded at all levels of description (morphological, syntactic and semantic), each in its own mode of capturing it, any ontology should include different types of information to be conflated in the proposed descriptive algorithm. At the level of morphological description, it should include part-of-speech basic information together with other collocational peculiarities of this particular lexical item. That is, once the basic part of speech classification has been completed, the morphosyntactic characterization should take the form of common parser, again complemented with collocational data. The main challenge, however, is to devise a system that allows for some kind of codification for those linguistic aspects which highly affect meaning, but which cannot be formalized along the same lines that logical or more directly referential lexical items do, such as it happens with metaphoric, metonymic and synesthetic linguistic resources.

The analysis of this extensive data base requires a certain methodological approach. It is proposed here that the computational analysis of the selected corpus should be tagged following a number of tagging descriptors that can be broadly classified into semantic descriptors and cognitive descriptors. Somewhere in the system encyclopaedic knowledge should also be inserted.

Table 1, in Appendixes section, shows how the description of each lexical item requires a number of separate semantic and cognitive entries, arranged along a cline. This is represented by means of a dotted line to express the fact that there is no claim made of a separation between cognitive and semantic approaches in the descriptive tagging components albeit the breakdown of them might suggest otherwise. The task to represent this conceptual overlapping, or this lack of clearly defined boundaries, which most 
probably will need the use of intervals, is left to mathematicians and computational experts.

A common parser providing morpho-syntactic information should not present processing problems in computational terms and most grammars of different affiliation have their own computational implementation. Pragmatic and discourse tagging is also linked to parsing.

In addition, and yet unspecified, somewhere along the these list of taggers, a specification stating whether this particular lexical item is in itself an operational instruction (logical or other) or not, should be included. This is important from the computational point of view because it will rule out the activation of the content of various subsequent slots as irrelevant.

Each lexical entry should then include both semantic and cognitive descriptors. Under the label of semantic tagging we include basic descriptors such as both, language dependent, part-of-speech and dictionary definition. The latter should be a well contrasted traditional onomasiological definition. Coseriu (1983), Martin Mingorance (1984, 1996), Faber and Mairal (1997, 1999), Mairal (2000), among others, have recognized the value of onomasiological definitions in their respective linguistic models.

The part-of-speech specification is essential because it frames subsequent parsing. The dictionary definition in turn will be framing the construction of an ontolgy which will be organized hierarchically according to the type of category.

We will then refer to type of category selecting a first, second or third order category (Lyons, 1977; Paradis, 2005). This specification obviously linked to part-of-speech is also connected to different kinds of profiling.

Next the type of logical construct should be included. These descriptors can also be placed next to the part-of-speech entry for the sake of clarification, but placing them next to the cognitive side helps understanding the following specifically cognitive taggers. The type of logical construct will feed information to be implemented in the parser, but it will also be connected with the kind of profile that the cognitive tagging as a whole suggests. The connection between the preferred profiling and the selected type of logical construct is to be developed elsewhere.

Cognitive tagging includes further specification to spell out each lexical item in terms of its cognitive interpretation in stretches of language. Part/whole, Degree/Frequency and Boundedness are all descriptors included at this stage. I take the view that, for operational and computa- tional reasons, all of them should be considered as relational constructs. The codification of all these different types of information will conflate taking the form of a descriptive algorithm to be attached to the particular lexical item.

The part-of-speech, dictionary definition and logical constructs have already been addressed in computational linguistics. It is the codification of the cognitive components what is more challenging and what still needs to be formalized in a straightforward way. And this is precisely what the restricted field of wine tasting description requires. How to account for these aspects and capture them in a particular tagger, specifically designed for this task, is one of the main challenges of the present work.

\section{Discussion}

The proposed methodology consists of a progressive reduction of the corpus until it reaches a manageable size. In order to do this what is been labelled as Clashing Identification $(\mathrm{Cl})$ is proposed.

Firstly, the lexical entries that can not be given a dictionary definition are by default the subcorpus in which to start searching for metaphors or other unconventional descriptions. That is the lexical entries without this annotation $(\Theta)$ will be sub corpus where other instructions are to be performed:

$$
\begin{aligned}
& \Sigma=\text { Wine Tasting Notes annotated corpus } \\
& \Sigma-\Xi=\text { manually taggeable corpus }
\end{aligned}
$$

Secondly, the part-of-speech component can also help factoring out a number of elements, leaving nouns and adjectives as the most likely head words supporting metaphor like constructions.

For example, from a probabilistic perspective space metaphors involving <part-of-speech: prepositions > are less likely to be found in wine tasting notes. This could be enough reason to provisionally leave out this <part-of -speech: preposition> component.

Because configuration involving $<$ part/whole $>(\mu)$, $<$ frequency $>(\varphi)$, <boundedness $>(\beta)$, <degree> $(\delta)$, are more frequently linked to adjectives and adverbs these subcomponents are to be linked to <perceptual input> $(\alpha)$, <part of speech> $(\gamma)$ and referent $(\Delta)$, to identify clashes.

Thirdly, parsing could be an adequate instrument to help disambiguating certain expressions. This in turn is expected to help identifying metaphoric expressions. 
In example 1, the entries for wine, beauty and aggressive can be compared. Here, the component type of ontological construct $(\sigma)$ for wine or beauty will be <entity>, whereas for aggressive will be <relation>. The component dictionary entry $(\Theta)$ for aggressive and beauty will clash with the component link to perceptual input $(\alpha)$ and it will be ruled out and not included in the description of the lexical item. Finally, wine and beauty both share $(\sigma)$ type of ontological construct, but they will clash in type of category (1st vs. 3rd order entity).

In example 2, entries for wine and beauty are discussed. The entry for wine is obviously present in any wine tasting guide. The entry for beauty has been taken from Robert Parker's Wine Advocate in (1)

(1) this beauty should drink well for 10-12 years

These two entries are both nouns but, whereas a dictionary entry is applicable in the case of wine, in the case of beauty, the metaphorical description is not compatible with a dictionary entry and therefore a clash can be identified. However, they are both different types of entities and in both cases a description of qualia is applicable.

In example 3 , the pair beauty / aggressive is analyzed. The component type of ontological construct $(\sigma)$ for beauty will be <entity>, whereas for aggressive will be <relation>. The component dictionary entry $(\boxminus)$ for aggressive and beauty will clash with the component link to perceptual input $(\alpha)$ and it will be ruled out and not included in the descriptive algorithm. This will help reduce the general corpus $(\Sigma)$ to a manually taggeable one $(\Sigma-Ð)$.

Finally, in example 4, the two entries corky / aggressive are compared. The component type of ontological construct $(\sigma)$ for corky and aggressive will be <relation>. Their respective diccionary entries $\langle\boxminus>$ read as follows:

$<$ A corked wine is a flawed wine that has taken on the smell of cork as a result of an unclean or faulty cork. It is perceptible in a bouquet that shows no fruit, only the smell of musty cork, which reminds me of wet cardboard $>\langle\overline{R P}\rangle$

$<$ adjective

$<$ Wine is described as being corked if its taste has been spoiled by the cork $><C D>$

On the other hand, the link to referent will exist in the case of corky but will not in the case of aggressive. This clashing will rule out dictionary definition $\langle\boxminus\rangle$ for aggressive and therefore lead to a metaphoric interpretation of either or both of the two.

\section{Conclusions}

The lexical field that codifies the sensory experiences of wine drinking has been selected because it constitutes a very adequate testing ground for trying out different alternatives in lexical codification. The proposed lexical codification takes the form of a descriptive algorithm which amalgamates various kinds of semantic and cognitive information.

In this paper I have tried to show how the description of each subfield calls for different representational tools. On the one hand, the most clearly referential terms in the field could have done with a similar referential description componentially based. On the other hand, sensory description requires not only highly synesthetic adjectivation, but most importantly, the peculiarities of the adjectivation used must be approached from a cognitive perspective which could account, among others, for boundary problems. In addition, the highly metaphoric type of description in wine tasting requires an approach which should be able to combine various perpectives.

The proposed descriptors take the form of an amalagamation of elements which can be attached to each lexical item or construction. The list of taggeable descriptors is organized along two main broad categories: semantic and cognitive. Each lexical piece or construction is specified for semantic description under part of speech, dictionary definition and type of ontological category. Under the cognitive description the part/whole, degree/ frequency and boundnes should be specified mainly as leading internal relations or functions. Somewhere in between, both kinds of logical constructs-predicate and qualia structure-are inserted. A general rule accounting for sequentiality will be appliable for all descriptors. Further specification will set the hierarchical relations among descriptors.

It is claimed here that this simple descriptive alghorithm, ontologically based and strongly field dependent, is basically a nuclear grammar to be computationally implemented.

\section{Notes}

(1) Malnicet al, 1999 show how one of the most basic characteristics of this complexity refers to the fact that one neural receptor recognizes multiple smells and, at the same time, one single odour is recognized by multiple receptors. At the same time the smell stimulus, which is performed through not mielinazied axons, is the slowest one compared with other sensory stimuli (Hertz \& Engen, 1996) and this signal is also relatively weaker (50000mitral cells) compared with the visual image 
which keeps a million pixels per retina cell (Holey \& Mac Leod,1977). These characteristics are associated with certain specific functions such that smells can modify some behaviours (Epple \& Hertz, 1999), generate emotions (Hertz, 1998; Kirk-Smith et al., 1983) or evoke past situations (Chu \& Downes, 2000). In addition, Richardson and Zucco (1989) explain how human beings have an excellent ability to detect and discriminate odours, but they also find it more difficult to detect and identify odourant sources. Wippich et al., (1989) conclude that smell is the most difficult sense when it comes to lexicalizing these experiences.

\section{References}

Bateman, John A. 2007. Linguistic interaction and ontological mediation. // A.Schalley and Diezmar Zaefferer (eds.). Ontolinguistics. How ontological status shapes the linguistic coding of concepts. Berlin.New York: Mouton de Gruyter,2007.

Coseriu, Eugenio (1983). Introducción a la lingüística. México. UNAM. Instituto de Investigaciones Filológicas. Publicaciones del Centro de Lingüística.1983.

Chu, S.; Downes, J. J. (2000). Odour- evoked autobiographical memories. // Psychological investigations on proustian phenomena. Chemical Senses. 25, 111-116.

Epple, G.; Hertz, R.S. (1999). Ambient odors associated to failure influence cognitive performance in children. // Development Psychobiology. 35 (1999) 193-107.

Faber, P. B.; Mairal, R. (1999). Constructing a Lexicon of the English Verb. Berlin: Mouton de Gruyter, 1999.

Faber, Pamela y Ricardo Mairal Usón (1997). Definitional Analysis in the Functional-Lexematic Lexicographic Model. // Alfinge. Revista de Filología. 9 (1997) 217-232.

Fellbaum, Christiane. (1998c). A semantic network of English verbs. // C. Fellbaum (ed ), WordNet; An electronic database. 69-104.

Fellbaum, Christiane. (ed) (1998a). WordNet; An electronic database. Cambridge, MA:MIT Press, 1998.

Gärdenfors, P. (2006). Does Semantics Need Reality?. // Riegler, A.; Peschl, M.; Stein, A. (eds). Understanding Representation in the Cognitive Sciences. Plenum Academic/ Kluwer Publishers, 2006.

Herdenstam, Anders P. F.; Richard Ahlström, and Per-Axel Wikrorsson. The professional language of wine-Studies on concept building and communication during tasting situation. Submitted to Journal of Wine Research and accepted for publication.

Herdenstam, Anders (2004). Experience of an aesthetic sensation: Wine tasters in the field between art and science. Lecentiate theis. Stockholm: Royal Institute of technology. Departmetnt of Economics and management.

Herz, R.; Engen, T. (1996). Odor memory: Review and analysis.// Psychonomic Bulletin \& Review, 3, 300-313.

Hertz, R. (1998). Are odors the best cues to memory?:A cross- modal comparison of associative memory stimuli. // Annals of the New York Academy of Sciences. 855 (1998) 670-674

Holey, A.; Mac Leod, P. (1977). Transduction and coding of olfactory information. // Journal of Physiologie. 73 (1977) 725-848.

Hopper, Paul J.; S. Thompson (1984). The discourse basis for lexical categories in universal grammar. // Language. 60 (1984) 703-752.

Johnson, M. (1987). The Body in the Mind: The Bodily Basis of Meaning, Imagination and Reason. Chicago, IL: University of Chicago Press, 1987.
Lakoff, G.; Thompson, M. (1980). Metaphors we live by. Chicago: The University of Chicago Press, 1980.

Langaker, R. (1991). Foundations of Cognitive Grammar. Vol II. Stanford, Ca.: Stanford University Press.

Lehrer, Adrienne J. (1983). Wine and conversation. Bloomington: Indiana University Press, 1983.

Lehrer, Adrienne J. (1985). Is semantics perception driven or network-driven? // Australian Journal of Linguistics. 5 (1985) 197-209.

Lehrer, Adrienne and Eva Feder Kittay (1992). Frames, Fields and Contrasts. Hillsdale New Jersey: Lawrence Earlbaum Associates, Publishers, 1992.

Lyons, J. (1977). Semantics. 2 vol. Cambridge: Cambridge University Press.

Lyons, J. (1995). Linguistic Semantics. Cambridge: Cambridge University Press, 1995.

Malnic, B.; Hirono, J.; Sato, T.; Buck, L.B. (1999) Combinatorial receptor codes for odors. Cell, 96, 713-723.

Mairal, R.; M. J. Pérez Quintero (2000). New Perspectives on Argument Structure in Funcional Grammar. Berlin: Mouton de Gruyter, 2000.

Martin Mingorance, L. (1996). Functional Grammar and Lexematics in Lexicography. // Tomaszczyk, J.; Lewandowska-Tomasxczyk, B. (eds). Meaning and Lexicography. Amsterdam: John Benjamins. Toope, M. 1996.

Martín Mingorance, Leocadio (1998). Semes, semantic classemens, and dimensions: the lexicological and lexicographic perspectives». // Martín Mingorance, Leocadio, El modelo lexemático-funcional. El legado lingüístico de Leocadio Martín Mingorance, (Martín Rubiales, A., ed.). Editorial Universidad de Granada: Granada, 1998.

Metzinger, t. and Vittorio Gallese. (2007). The emergence of a shared action ontology: Building blocas of a theory. // Schalley, Andrea and Dietmar Zaefferer edts. 2007. Ontolinguistics. How Ontological Status Shapes the Linguistic Coding of Concepts. Berlin: Mouton de Gruyter.

Moreno. A.; Pérez, C. (2000) Ontological semantics and lexical templates. // Mairal, R. \& M. J. Pérez Quintero New Perspectives on Argument Structure in Funcional Grammar. Berlin: Mouton de Gruyter.

Tomaszczcyk, J. and Lewandowska-Tomaszczyk, B. eds. (1990) Meaning and. Lexicography. Amsterdam: John Benjamins. Toope, M. 1996

Morot, G. , F. Brochet and D. Dubourdieu (2001) The colour of odors. Brain and Language 79, 309-320.

Nickles, Matthias; Adam Pease, Andrea C. Schalley and Dietmar Zaefferer.(2007) Ontologies across disciplines. // Andrea Schalley, and Dietmar Zaefferer edts. Ontolinguistics. How Ontological Status Shapes the Linguistic Coding of Concepts. Berlin: Mouton de Gruyter.2007.

Onishi, Masayuki (1994). Semantic Primitives in Japanese. // Cliff Goddard and A. Wierzbizcka (eds) Semantic and Lexical Universals. The Netherlands- USA: John Benjamins, 1994.

Paradis, C. (2004) Where does metonymy stops? Senses, facets and active zones. // Metaphor and Symbol. 19:4 (2004) 245-264.

Paradis, C. 2005. Ontologies and Construals in Lexical Semantics. // Axiomathes. 15 (2005) 541-573.

Paradis, C. 2007. Configurations, construals and change expressions of degree. Submitted to English Language and Linguistics.

Popova, Y. (2003) The fool sees with his nose: metaphoric mappings in the sense of smell in Patrick Süskind's Perfume. // Language and Literature SAGE Publications (London, Thousand Oaks, CA and New Delhi), Vol 12(2): 135-151.

Schalley, Andrea; Zaefferer, Dietmar (2007). OntolinguisticsAn outline. // Schalley, Andrea; Zaefferer, Dietmar (eds.). Ontolinguistics. How Ontological Status Shapes the Lin- 
guistic Coding of Concepts. Berlin: Mouton deGruyter.2007.

Schalley, Andrea; Zaefferer, Dietmar (eds.) (2007). Ontolinguistics. How Ontological Status Shapes the Linguistic Coding of Concepts. Berlin: Mouton deGruyter, 2007.

Schmid, Hans-Jörg (2000). Semantic prerequisites. Abstractness. // Schmid, Hans-Jörg (ed.). English abstract nouns as conceptual shell. From corpus to cognition. Berlin-New York: Mouton de Gruyter, 2000.

Smith, Barry; Brogaard, Berit (2003). A unified theory of truth and reference. // Logique et Analyse. 43:169-170 (2003) 49-93.

Sweetser, E.E. (1990). From Etymology to Pragmatics: Metaphorical and Cultural Aspects of Semantic Structure. Cambridge: Cambridge University Press, 1990.

Viberg, A. (1984). The Verbs of Perception: a Typological Study. // B. Butterworth, B. Comrie and D. Osten (eds).
Explanations for Language Universals. 123-62. Berlin: Mouton. Watson, L., 2000.

Wierzbicka, Anna (1986). What is a noun(or: how do nouns differ in meaning from adjectives?). // Studies in Language. 10 (1986) 353-89.

Wippich, W.; Meckelbrauker, S.; Trouet, J. (1989). Implicit and explicit memories of odors. Archiv fur Psychologie. 141 (1989) 195-211.

Zucchi, A. (1993) The language of propositions and events. The Netherlands: Kluwer Academic Publishers, 1993.

\section{Wine Gides}

Peñín, José. (2006), (2007). Guía Peñín de los vinos de España. Madrid: Pi \&Erre Comunicación Integral, 2007.

Paker, R. The Wine Advocate. (2007).

\section{Appendix}

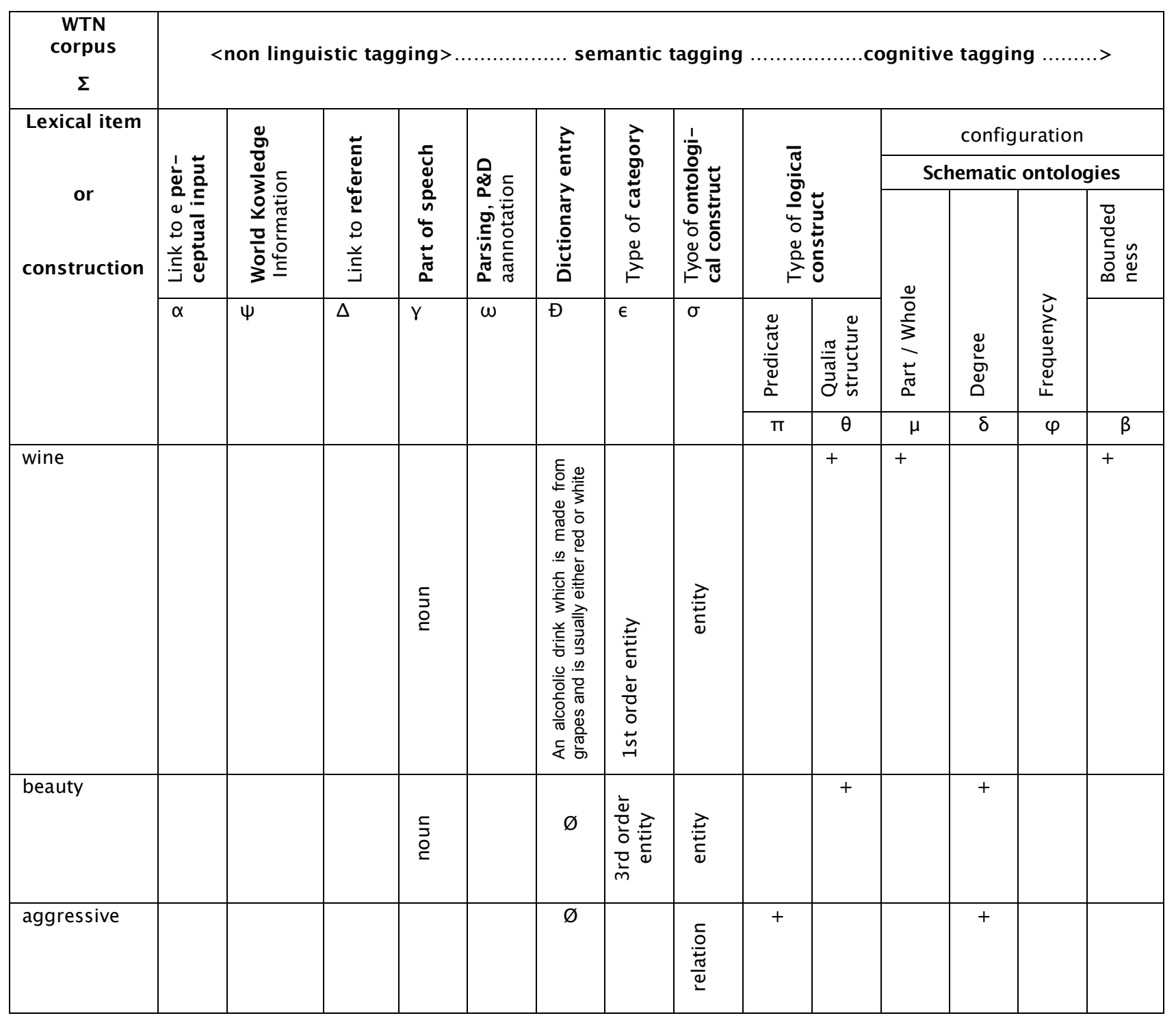

* Definition from Collins Cobuild Dictionary. 